\title{
Trajectories of family care over the lifecourse: evidence from Canada
}

\author{
Janet Fast ${ }^{1 \star}$ (D), Norah Keating ${ }^{1,2,3}$, Jacquie Eales ${ }^{1}$, Choong Kim ${ }^{3}$ and Yeonjung Lee \\ ${ }^{1}$ University of Alberta, Edmonton, Canada, ${ }^{2}$ North-West University, Vaal Triangle, South Africa, \\ ${ }^{3}$ Swansea University, Swansea, UK and ${ }^{4}$ University of Calgary, Calgary, Canada \\ *Corresponding author. Email: jfast@ualberta.ca
}

(Accepted 20 November 2019; first published online 8 January 2020)

\begin{abstract}
In the midst of a 'care crisis', attention has turned again to families who are viewed both as untapped care resources and as disappearing ones. Within this apparent policy/demographic impasse, we test empirically theorised trajectories of family care, creating evidence of diverse patterns of care across the lifecourse. The study sample, drawn from a Statistics Canada national survey of family care, comprised all Canadians aged 65 and older who had ever provided care $(\mathrm{N}=3,299)$. Latent Profile Analysis yielded five distinct care trajectories: compressed generational, broad generational, intensive parent care, career care and serial care. They differed in age of first care experience, number of care episodes, total years of care and amount of overlap among episodes. Trajectories generally corresponded to previously hypothesised patterns but with additional characteristics that added to our understanding of diversity in lifecourse patterns of care. The five trajectories identified provide the basis for further understanding how time and events unfold in various ways across lifecourses of care. A gap remains in understanding how relationships with family and social network members evolve in the context of care. A challenge is presented to policy makers to temper a 'families by stealth' policy approach with one that supports family carers who are integral to health and social care systems.
\end{abstract}

Keywords: family care trajectories; lifecourse; family care history

\section{Introduction and rationale}

The language of population ageing is now embedded in national discourses about the wellbeing of societies and their members. In the Global North, drivers of population ageing such as low birth rates, increased longevity and improved survival of people with disabilities have been celebrated as evidence of effective public health strategies (Crosignani, 2010; Public Health Agency of Canada, 2014; Kingston et al., 2018). Similarly, in an effort to value all lives, the United Nations has resolved to leave no one behind (Office of the United Nations High Commissioner for Human Rights, 2011).

(C) The Author(s), 2020. Published by Cambridge University Press. This is an Open Access article, distributed under the terms of the Creative Commons Attribution licence (http://creativecommons.org/licenses/by/4.0/), which permits unrestricted re-use, distribution, and reproduction in any medium, provided the original work is properly cited. 
These celebratory conclusions about the positive outcomes of population ageing stand in stark contrast to those that long ago were branded as 'apocalyptic demography' (Robertson, 1997). Considerable alarm about the negative impact of population ageing still resonates in every sector from housing (Lund, 2017) to income security (Grech, 2018). Among these is widespread concern about a 'crisis in care' resulting from increased numbers of older people, with higher levels of disability and reduced funding to support them (Deusdad et al., 2016; Jagger, 2017). Evidence is mounting of frail older people with unmet needs for support (Humphries et al., 2016) and who are at risk of social isolation and loneliness (Smith and Victor, 2019).

\section{Contexts of family care}

In the midst of this framing of a care crisis, attention has turned again to families as central players in the solution. Tronto (2017: 30) argues that the resurgence of families as the proper locus of care is an expected response from neoliberal societies that believe, 'if people are now less well cared for, it must, by definition, be a failure of their own personal or familial responsibility'. In many countries efforts are under way to maximise family care capacity through policy levers and campaigns to prepare people to care (Employment and Social Development Canada, 2016), positioning adults as personally responsible for assuming the carer role and for the financial and social implications that flow from it. Analysts in the United Kingdom (UK) note inherent tensions between expectations to do more to support older relatives and pressures to stay longer in employment (Starr and Szebehely, 2017). In their analysis of public policy across countries in Europe and Asia, Kodate and Timonen (2017: 301) see a variety of approaches to increasing, encouraging and necessitating family care inputs. Their common feature is the 'stealthily growing role of family carers'.

Alongside policy settings that reflect a search for more family care is the demographic context that points to reduced family care capacity. The hallmarks of population ageing - lower birth rates and increased longevity - mean that families have fewer younger members to care for older generations (Redfoot et al., 2013). Increased geographic mobility and high labour force engagement raise concerns about care gaps resulting from unavailability of family members who might otherwise be carers (Scharlach et al., 2007; Young and Grundy, 2008). Family fluidity resulting from high divorce rates and diverse partnership arrangements results in diffuse care obligations (Fingerman et al., 2012; Connidis and Barnett, 2019). One might conclude that while the policy context is one of 'family care by stealth', the demographic context is of 'stealthily disappearing family carers'.

In the face of these macro policy discourses and demographic trends about care gaps, researchers have been creating evidence that families have not disappeared but are making substantial contributions to the lives of those with chronic health problems and disabilities (Hoff, 2015; Ankuda and Levine, 2016). Yet also there is growing evidence of negative impact on their social connections, financial wellbeing and health (Bauer and Sousa-Poza, 2016; Keating and Eales, 2017).

It is within this setting of high levels of costs to carers and their substantial contributions that Starr and Szebehely (2017) remind us of the danger of thinking 
about families as the panacea for care gaps. The question is how to move beyond the apparent impasse of conflicting discourses about families as present or absent, with untapped care capacity or overwhelmed.

The goal of this paper is neither to advance the search for unused family care capacity nor to establish its futility but to create a more nuanced understanding of family care as a basis for challenging stealth discourses. In the study described in this paper, we present data from a national survey of family carers that illustrates diversity in care to a variety of family members across broad sweeps of the lifecourse.

\section{Lifetimes of family care}

The call for more research on family care may seem unwarranted given the extensive body of research on family care. We know a great deal about what family carers do (e.g. Cès et al., 2017) and who they care for (e.g. Grossman and Webb, 2016). However, most studies to date are focused on a period of care to a specific care receiver such as a parent or a spouse; or by carers at a particular place in the lifecourse (e.g. young carers, mid-life carers, older carers). These snapshots of care do not account for the likelihood that, over a long sweep of time, a person may have multiple care experiences that build on one another.

Care trajectories and cumulative costs for family carers have been largely ignored, despite a small amount of evidence that family care can involve multiple episodes with diverse patterns and consequences across the lifecourse (Fast et al., 2013; Lunsky et al., 2017). A better understanding of lifetime patterns of care would enhance our knowledge of family care experiences in important ways. Do young carers continue to care throughout their lives? Do those caring for parents subsequently care for spouses, older relatives or friends? Importantly, how might these patterns differ from each other in ways that influence carers' ability or willingness to assume further care responsibilities? Addressing these questions can, in turn, inform our understanding of cumulative advantage and disadvantage (Carmichael and Ercolani, 2016) in ways that make clear the deficiencies of relying on evidence about current episodes of care for research, policy or practice purposes.

Such an exploration seems timely given the families by stealth discourses. It seems timely as well given growing evidence that family care has become a normative part of the lifecourse. A national survey in Canada (Sinha, 2013) showed that, in a single year, 28 per cent of Canadians over age 15 had provided care to a family member or friend. But nearly half $(46 \%)$ said they had provided care at some time in their lives. Estimates are even higher in the UK where 60 per cent are expected to be carers at some point in their lives (Carers UK, 2015). In this paper we begin this exploration by reporting on the results of an empirical examination of lifecourses of family care of older Canadians.

\section{Framing the research on lifecourses of family care}

The conceptual framing of this research comes from Keating et al. (2019) who proposed a lifecourse domain of family care grounded in lifecourse assumptions that transitions and trajectories create the structure and rhythm of individual lives 
(Alwin, 2012; Elder and George, 2016). They conceptualise care as having components of both 'doing tasks' and 'being in relationships' that evolve over time. Family carers are distinguished by their close kin connections or long-standing friendships with the cared-for person. Family care trajectories, then, are patterns of moving into and out of episodes of care and the evolution of close relationships across time. They are bounded by bookends that mark the beginning and end of lifecourses of family care. Informed by these conceptual building blocks and empirical evidence, Keating et al. (2019) hypothesised three family care trajectories which they labelled generational, career and serial.

In the Methodology section of the paper we operationalise the proposed family care trajectory building blocks and create empirical lifecourse trajectories which we then compare to those that were hypothesised.

\section{Methodology}

\section{Data}

Statistics Canada's General Social Survey Cycle 26 on Caregiving and Care Receiving provided the opportunity to examine lifecourse patterns of care as it included retrospective data on care provided by family carers across the lifecourse and its consequences. In the survey, care was operationalised as having provided help to a family member or friend of any age with a long-term health condition, physical or mental disability, or with a problem related to ageing. Data collection occurred between March 2012 and January 2013 using random digit dialling and computer-assisted telephone interviewing. The overall response rate for the survey was 65.7 per cent, yielding a full sample of 23,093 respondents representative of the population of all individuals aged 15 and older living in the ten Canadian provinces (excluding residents of the Yukon, Northwest Territories and Nunavut, and institutionalised persons).

\section{Sample}

For this study, we selected a sub-sample of respondents aged $65+$ who had ever provided care to a family member or friend. Respondents aged 65 and older were expected to have the most complete care histories (though it should be noted that some will engage in additional care episodes in the future). The final sample for this study comprised all respondents age 65 and older who had ever provided family care $(\mathrm{N}=3,299)$. Taken to the population level, they represent 2.1 million Canadians over age 65, or half of all non-institutionalised older adults living in the ten Canadian provinces.

\section{Operationalisation of variables}

We follow the identification of Keating et al. (2019) of the key elements of trajectories as bookends that mark the start and end of a lifecourse of care; care episodes that are periods of care to an individual; and the sequencing of these care episodes across time. Based on these key elements, we operationalised four components of care trajectories: age of onset of the first care episode (representing the first 
bookend); number of episodes of care in the individual's lifecourse (to a maximum of $\operatorname{six}^{1}$ ); total duration of all episodes of care; and the extent to which episodes overlapped one another. These comprised the independent variables used in the Latent Profile Analysis (LPA).

Age at onset of the care trajectory is the age at which a respondent carer reported entering into their first episode of care. Responses ranged from age 4 to age 92 . This variable was treated as continuous in the LPA. (The final bookend of the care trajectory could not be assessed as future engagement in care cannot be predicted.) Number of care episodes is a count of the number of times during their lifecourse that the respondent provided care to a family member or friend, to a maximum of six. Responses ranged from one to six and was treated as a count variable in the LPA. Total duration of care was the sum of the length of all care episodes reported, excluding overlapping years (i.e. times during which the respondent was caring for more than one person at the same time were counted only once). The total duration ranged from one to 64 years and was treated as a count variable in the LPA. Sequencing is represented by a count of total number of years in which respondents reported overlapping episodes of care. Years of overlap ranged from one to 57 and was treated as a count variable in the LPA.

In order to characterise the care trajectories further we also examined factors relevant to family care: carer sex; relationship between the carer and their care receiver; and age at start and end of each care episode. Sex was a dichotomous variable indicating whether the carer was male or female. Relationship to the care receiver for each care episode included the categories of spouse (including co-habiting partners and former spouses), child (including children-in-law), parent (including parents-in-law), sibling (including brothers and sisters-in-law), other kin or non-kin (including friends, neighbours and work colleagues) of the carer. For each care episode age at start and age at end of the episode was a continuous variable determined from respondents' reports.

\section{Analyses}

To address our research questions, LPA and cross-tabulations were conducted. All analyses were weighted using survey weights provided by Statistics Canada to ensure that model parameter estimates represented the target population of persons in Canada over the age of 65 (excluding residents of the Yukon, Northwest Territories and Nunavut, and institutionalised persons), who had ever provided care to a family member or friend.

\section{Creating the care trajectories}

We used LPA to identify care trajectories among our sample of carers aged 65 and older based on the four core variables: age at first transition into care, number of care episodes, duration of care and years of overlap (operationalised above). LPA is one of several person-centred statistical approaches to mixture modelling that categorises individuals into substantively meaningful, homogeneous sub-groups based on patterns of association among independent variables (Nylund et al., 2007; Dyer and Day, 2015). LPA is appropriate when analyses are conducted with either continuous or a mix of continuous and discrete variables (Galovan 
and Schramm, 2017; Galovan et al., 2018). LPA is also useful for this study because it allows us to assign respondents to a particular care trajectory type based on the estimated probability of membership in that group. This can then be used in analyses to describe further the characteristics of each care trajectory.

LPA is superior to other mixture modelling techniques in capturing complex patterns among multiple characteristics, relying as it does on more objective and rigorous fit indices and other criteria to uncover distinctive sub-groups of people (Stanley et al., 2017). For this study, the LPA was conducted using maximum likelihood estimation and multiple fit indices (Bayesian Information Criterion, sample-adjusted Bayesian Information Criterion, Akaike Information Criterion, Vuong-Lo-Mendell-Rubin likelihood ratio test) and entropy (Nylund et al., 2007).

\section{Describing care trajectories}

We cross-tabulated each of the five care trajectory profiles with the four core characteristics entered into the LPA along with additional characteristics important in understanding patterns of care: relationship between carers and care receivers, age of entry into and exit from each episode, and sex of carer.

\section{Findings}

In this section of the paper we report findings from the LPA and detailed descriptions of the five trajectory types identified by the LPA.

\section{Creating care trajectory profiles}

LPA analyses allowed us to determine whether groups of family carers with similar lifecourse patterns of care, based on four care trajectory components, could be detected and how many distinct patterns of care could be identified.

Table 1 shows the fit indices for the latent class models with two to six classes. Model fit indices and substantive interpretation indicated that a five-class solution best fit the data. Overall, these classes were well differentiated as evidenced by entropy values greater than 0.9 . Figure 1 illustrates the fit indices for the models graphically. The slope can be seen to drop sharply between the two- and three-class, and the three- and four-class models and flatten between the four- and five-class models. Although the six-class solution does improve model fit, the gain is small and results in a class that applies to only 2.8 per cent of the sample, conditions that Dyer and Day (2015) advise should be treated with caution. The five-class model also better matches the theoretical assumptions about lifecourse care trajectories, and the theorised trajectory types (Keating et al., 2019), while creating a more nuanced understanding of lifecourse diversity.

\section{Describing care trajectories}

Each of the five care trajectories that emerged from the LPA is distinguished by its unique cluster of characteristics. Based on our examination of all of these characteristics we labelled the five care trajectories: compressed generational, broad generational, intensive parent care, career, and serial. Each is described below based on 
Table 1. Fit indices for latent profile class models

\begin{tabular}{lcccccc}
\hline Model & Log likelihood & AIC & BIC & SABIC & VLMR $(p)$ & Entropy \\
\hline Two classes & $-35,238.697$ & $70,497.394$ & $70,558.408$ & $70,526.634$ & 0 & 0.934 \\
\hline Three classes & $-33,231.856$ & $66,493.711$ & $66,585.232$ & $66,537.570$ & 0.0165 & 0.901 \\
\hline Four classes & $-32,010.858$ & $64,061.717$ & $64,183.744$ & $64,120.196$ & 0.0609 & 0.921 \\
\hline Five classes & $-31,231.084$ & $62,512.167$ & $62,664.701$ & $62,585.265$ & 0.0020 & 0.910 \\
\hline Six classes & $-30,973.270$ & $62,006.540$ & $62,189.581$ & $62,094.258$ & 0.0459 & 0.902 \\
\hline
\end{tabular}

Notes: $\mathrm{N}=3,299$. AIC: Akaike Information Criterion. BIC: Bayesian Information Criterion. SABIC: sample-adjusted Bayesian Information Criterion. VLMR: Vuong-Lo-Mendell-Rubin likelihood ratio test.

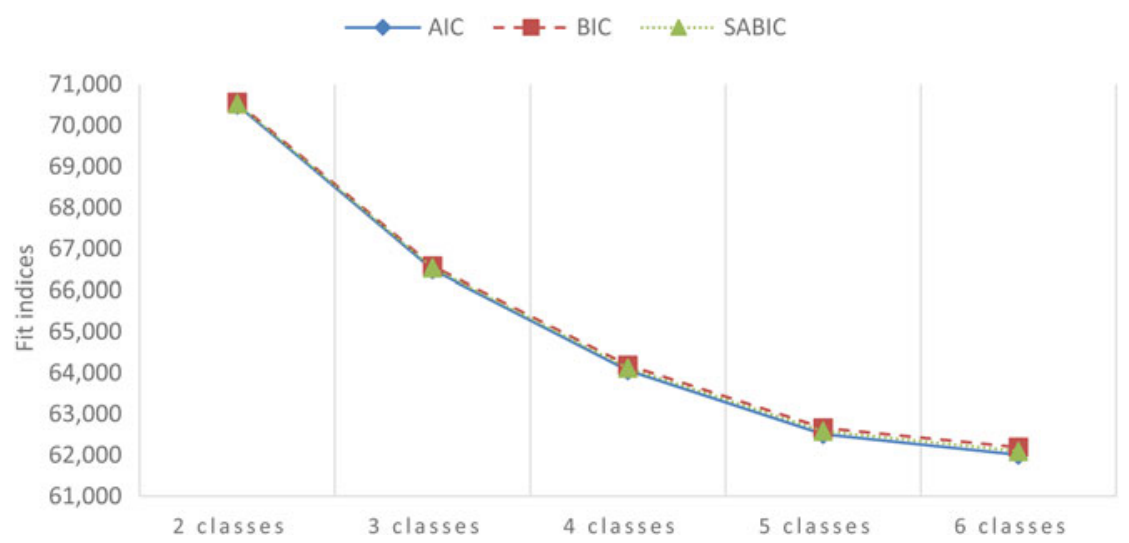

Figure 1. Results of Latent Profile Analysis.

Notes: AIC: Akaike Information Criterion. BIC: Bayesian Information Criterion. SABIC: sample-adjusted Bayesian Information Criterion.

core care trajectory components (Table 2), sex (Table 3), age of entry into and exit from each care episode (Table 4), and carer-care receiver relationship for each episode (Table 5).

\section{Compressed generational trajectory}

The compressed generational trajectory is the most common $(\mathrm{N}=1,744 ; 54 \%)$. Compared to the other trajectories, it had the oldest average age of onset (63.1 years), the smallest number of episodes (1.16), shortest total duration (3.8 years on average) and almost no overlap among care episodes ( 0.05 years). Just over half of carers in this trajectory were women (57.2\%). There is little evidence of sequencing for this trajectory type as only 13 per cent of carers reported a second care episode. For those who did, subsequent care episodes occurred within a compressed time-frame, following shortly on the first care episode. Most cared for close kin (spouses or parents). Overall, the defining feature of the compressed generational trajectory is a single, short period of care in later life within high-obligation older or same-generation close kinship ties. 
Table 2. Weighted means of core characteristics by care trajectory type

\begin{tabular}{lccccc}
\hline & $\begin{array}{c}\text { Compressed } \\
\text { generational }\end{array}$ & $\begin{array}{c}\text { Broad } \\
\text { generational }\end{array}$ & $\begin{array}{c}\text { Intensive } \\
\text { parent care }\end{array}$ & $\begin{array}{c}\text { Career } \\
\text { care }\end{array}$ & $\begin{array}{c}\text { Serial } \\
\text { care }\end{array}$ \\
\hline $\begin{array}{l}\text { Number of } \\
\text { episodes }\end{array}$ & 1.16 & 1.44 & 2.67 & 1.60 & 3.23 \\
$\begin{array}{l}\text { Age at first } \\
\text { transition }\end{array}$ & 63.08 & 51.53 & 52.43 & 34.17 & 36.25 \\
$\begin{array}{l}\text { Total } \\
\text { duration }\end{array}$ & 3.82 & 13.82 & 10.86 & 33.10 & 31.10 \\
\hline $\begin{array}{l}\text { Years of } \\
\text { overlap }\end{array}$ & 0.05 & $0.05^{1}$ & 4.45 & $0.51^{1}$ & 13.82 \\
\hline $\mathrm{N}$ & 1,744 & 815 & 363 & 203 & 144 \\
\hline
\end{tabular}

Notes: $\mathrm{N}=3,299$. 1 . Use with caution.

Table 3. Sex distribution by care trajectory type

\begin{tabular}{|c|c|c|c|c|c|}
\hline & $\begin{array}{l}\text { Compressed } \\
\text { generational }\end{array}$ & $\begin{array}{c}\text { Broad } \\
\text { generational }\end{array}$ & $\begin{array}{c}\text { Intensive } \\
\text { parent care }\end{array}$ & $\begin{array}{l}\text { Career } \\
\text { care }\end{array}$ & $\begin{array}{c}\text { Serial } \\
\text { care }\end{array}$ \\
\hline \multicolumn{6}{|c|}{ Percentages } \\
\hline Male & 42.8 & 40.7 & 35.8 & 36.9 & 29.0 \\
\hline Female & 57.2 & 59.3 & 64.2 & 63.1 & 71.1 \\
\hline $\mathrm{N}$ & 1,744 & 815 & 363 & 203 & 144 \\
\hline
\end{tabular}

Note: $\mathrm{N}=3,299$.

\section{Broad generational trajectory}

The broad generational trajectory is the second most common $(\mathrm{N}=815 ; 25 \%)$. It is characterised by mid-life onset (51.5 years on average) and an average of 1.4 care episodes with a total average duration of 13.8 years. The first care episode was relatively long (10 years on average). More than one-third of carers (37\%) reported a second, shorter episode in their late fifties to early sixties, while 8 per cent reported a third. However, there was almost no overlap among episodes ( 0.05 years on average). Nearly 60 per cent of carers in this trajectory were women (59.3\%). Most cared for close kin of same or older generations (parents or spouses), especially in the first episode. Later care episodes increasingly involved non-kin. Defining features of the broad generational trajectory are a first long episode of care in mid-life followed by shorter episodes, increasingly to same-generation close friends, neighbours and other non-kin. The broad generational trajectory highlights the fact that care goes beyond close kin relationships.

\section{Intensive parent care trajectory}

The intensive parent care trajectory comprises a smaller proportion of the study sample $(\mathrm{N}=363 ; 11 \%)$. It is characterised by mid-life onset (average 52.4 years) and an average of 2.7 care episodes with a total average duration of 10.9 years. 
Table 4. Episode characteristics by care trajectory type

\begin{tabular}{|c|c|c|c|c|c|c|c|c|c|c|c|c|c|c|c|}
\hline \multirow[b]{2}{*}{ Episode } & \multicolumn{3}{|c|}{ Compressed generational } & \multicolumn{3}{|c|}{ Broad generational } & \multicolumn{3}{|c|}{ Intensive parent care } & \multicolumn{3}{|c|}{ Career care } & \multicolumn{3}{|c|}{ Serial care } \\
\hline & $\%$ & Start & End & $\%$ & Start & End & $\%$ & Start & End & $\%$ & Start & End & $\%$ & Start & End \\
\hline 1 & 100 & 63.08 & 65.57 & 100 & 51.53 & 62.00 & 100 & 52.43 & 58.00 & 100 & 34.17 & 60.67 & 100 & 36.25 & 53.03 \\
\hline 2 & 13 & 62.78 & 64.31 & 37 & 59.01 & 63.73 & 100 & 55.97 & 61.29 & 44 & 55.53 & 65.39 & 100 & 44.57 & 60.21 \\
\hline 3 & 2 & 66.25 & 67.40 & 8 & 61.10 & 64.70 & 48 & 62.15 & 66.02 & 15 & 60.63 & 68.16 & 66 & 54.12 & 65.18 \\
\hline 4 & $<1$ & $-{ }^{1}$ & $-^{1}$ & $<2$ & 59.85 & 62.85 & 16 & 64.03 & 67.38 & $<8$ & 65.65 & 73.25 & 38 & 53.74 & 65.88 \\
\hline 5 & $<1$ & $-^{1}$ & $-^{1}$ & $<2$ & $-^{1}$ & $-^{1}$ & $<10$ & 66.98 & 69.65 & $<8$ & $-^{1}$ & $-{ }^{1}$ & $<25$ & 54.73 & 67.80 \\
\hline 6 & $<1$ & $-^{1}$ & $-^{1}$ & $<2$ & $-^{1}$ & $-^{1}$ & $<10$ & 67.86 & 71.13 & $<8$ & $-^{1}$ & $-^{1}$ & $<10$ & 66.91 & 73.06 \\
\hline $\mathrm{N}$ & \multicolumn{3}{|c|}{1,744} & \multicolumn{3}{|c|}{815} & \multicolumn{3}{|c|}{363} & \multicolumn{3}{|c|}{203} & \multicolumn{3}{|c|}{144} \\
\hline
\end{tabular}

Notes: $\mathrm{N}=3,299$. 1 . Too unreliable to be published. 
Table 5. Relationship between carer and care receiver for each care episode by care trajectory

\begin{tabular}{|c|c|c|c|c|c|}
\hline & $\begin{array}{l}\text { Compressed } \\
\text { generational }\end{array}$ & $\begin{array}{c}\text { Broad } \\
\text { generational }\end{array}$ & $\begin{array}{l}\text { Intensive parent } \\
\text { care }\end{array}$ & $\begin{array}{l}\text { Career } \\
\text { care }\end{array}$ & $\begin{array}{l}\text { Serial } \\
\text { care }\end{array}$ \\
\hline & & & Percentages & & \\
\hline \multicolumn{6}{|c|}{ First episode: } \\
\hline$N$ & 100 & 100 & 100 & 100 & 100 \\
\hline Spouse & 28.3 & 23.9 & $7.5^{1}$ & 22.7 & $--^{2}$ \\
\hline Children & $2.9^{1}$ & $2.5^{1}$ & -2 & $17.6^{1}$ & $--^{2}$ \\
\hline Parents & 38.5 & 52.2 & 68.4 & 42.3 & 67.0 \\
\hline Siblings & 10.2 & $4.8^{1}$ & $6.9^{1}$ & $--^{2}$ & $--^{2}$ \\
\hline Other kin & $3.0^{1}$ & $4.8^{1}$ & $4.1^{1}$ & $--^{2}$ & $--^{2}$ \\
\hline Non-kin & 17.0 & 11.8 & 10.5 & $6.9^{1}$ & $10.0^{1}$ \\
\hline \multicolumn{6}{|c|}{ Second episode: } \\
\hline$N$ & 13 & 37 & 100 & 44 & 100 \\
\hline Spouse & $11.1^{1}$ & 14.5 & $6.5^{1}$ & $17.6^{1}$ & $8.4^{1}$ \\
\hline Children & $--^{2}$ & $--^{2}$ & -2 & $--^{2}$ & $--^{2}$ \\
\hline Parents & 42.4 & 41.7 & 58.1 & $36.9^{1}$ & 59.0 \\
\hline Siblings & $11.5^{1}$ & $10.7^{1}$ & $8.4^{1}$ & $16.0^{1}$ & $10.0^{1}$ \\
\hline Other kin & $--^{2}$ & $5.3^{1}$ & $5.5^{1}$ & $--^{2}$ & $9.8^{1}$ \\
\hline Non-kin & 24.4 & 24.4 & 20.0 & $21.7^{1}$ & $9.4^{1}$ \\
\hline \multicolumn{6}{|c|}{ Third episode: } \\
\hline N & 2 & 8 & 48 & 15 & 66 \\
\hline Spouse & -2 & $14.6^{1}$ & $15.6^{1}$ & -2 & $--^{2}$ \\
\hline Children & $--^{2}$ & $--^{2}$ & -2 & $--^{2}$ & $--^{2}$ \\
\hline Parents & $--^{2}$ & $34.8^{1}$ & 32.4 & $46.4^{1}$ & 36.1 \\
\hline Siblings & -2 & -2 & $13.9^{1}$ & -2 & $14.9^{1}$ \\
\hline Other kin & $--^{2}$ & $--^{2}$ & $11.9^{1}$ & $--^{2}$ & $11.4^{1}$ \\
\hline Non-kin & $--^{2}$ & $32.7^{1}$ & 25.3 & $--^{2}$ & $22.6^{1}$ \\
\hline \multicolumn{6}{|c|}{ Fourth episode: } \\
\hline$N$ & $<1$ & $<2$ & 16 & $<8$ & 38 \\
\hline Spouse & -2 & $-{ }^{2}$ & $--^{2}$ & $--^{2}$ & $--^{2}$ \\
\hline Children & $--^{2}$ & $--^{2}$ & $--^{2}$ & $--^{2}$ & $-{ }^{2}$ \\
\hline Parents & $-{ }^{2}$ & $--^{2}$ & $30.6^{1}$ & -2 & $25.9^{1}$ \\
\hline Siblings & -2 & $--^{2}$ & $--^{2}$ & $--^{2}$ & $--^{2}$ \\
\hline Other kin & -2 & $--^{2}$ & -2 & -2 & -2 \\
\hline Non-kin & -2 & $-{ }^{2}$ & $29.5^{1}$ & -2 & $19.5^{1}$ \\
\hline
\end{tabular}


Table 5. (Continued.)

\begin{tabular}{|c|c|c|c|c|c|}
\hline & $\begin{array}{l}\text { Compressed } \\
\text { generational }\end{array}$ & $\begin{array}{c}\text { Broad } \\
\text { generational }\end{array}$ & $\begin{array}{l}\text { Intensive parent } \\
\text { care }\end{array}$ & $\begin{array}{l}\text { Career } \\
\text { care }\end{array}$ & $\begin{array}{l}\text { Serial } \\
\text { care }\end{array}$ \\
\hline \multicolumn{6}{|c|}{ Fifth episode: } \\
\hline $\mathrm{N}$ & $<1$ & $<2$ & $<10$ & $<8$ & $<25$ \\
\hline Spouse & $--^{2}$ & $--^{2}$ & $--^{2}$ & $--^{2}$ & $--^{2}$ \\
\hline Children & -2 & -2 & $--^{2}$ & $--^{2}$ & -2 \\
\hline Parents & $-{ }^{2}$ & $-{ }^{2}$ & $-{ }^{2}$ & $-{ }^{2}$ & $-{ }^{2}$ \\
\hline Siblings & -2 & -2 & -2 & -2 & -2 \\
\hline Other kin & $--^{2}$ & $--^{2}$ & $--^{2}$ & $--^{2}$ & $--^{2}$ \\
\hline Non-kin & -2 & $-{ }^{2}$ & 68.9 & -2 & $47.5^{1}$ \\
\hline \multicolumn{6}{|c|}{ Sixth episode: } \\
\hline $\mathrm{N}$ & $<1$ & $<2$ & $<10$ & $<8$ & $<0$ \\
\hline Spouse & $--^{2}$ & $--^{2}$ & $--^{2}$ & $--^{2}$ & -2 \\
\hline Children & $--^{2}$ & $--^{2}$ & $--^{2}$ & $--^{2}$ & $--^{2}$ \\
\hline Parents & -2 & $--^{2}$ & $-^{2}$ & $--^{2}$ & $--^{2}$ \\
\hline Siblings & -2 & -2 & $--^{2}$ & -2 & -2 \\
\hline Other kin & -2 & $--^{2}$ & $--^{2}$ & $--^{2}$ & $--^{2}$ \\
\hline Non-kin & $--^{2}$ & $--^{2}$ & $85.0^{1}$ & $--^{2}$ & $--^{2}$ \\
\hline $\mathrm{N}$ & 1,744 & 815 & 363 & 203 & 144 \\
\hline
\end{tabular}

Notes: 1. Use with caution. 2. Too unreliable to be published.

There were nearly 5 years of overlap among care episodes (average 4.5 years). More than 60 per cent of carers in this trajectory were women (64.2\%). All carers in this trajectory type had two care episodes, almost half (48\%) had a third and a smaller proportion had a fourth episode (data are suppressed for some later episodes because of small cell sizes). Sequencing of these care episodes reflected periods of overlap as well as short gaps across a moderately long period. Care to parents dominated these episodes with little generational sequencing. The defining feature of the intensive parent care trajectory is a decade or more in mid-life of providing care to parents (in-law), often caring for more than one parent at the same time.

\section{Career care trajectory}

The career care trajectory is relatively uncommon with only 6 per cent $(\mathrm{N}=203)$ of carers fitting this profile. Compared to the other trajectories, it had the youngest average age of onset (34.2 years) and longest total duration (average 33.1 years). It had 1.6 care episodes on average with little overlap among them ( 0.5 years on average). More than 60 per cent of carers in this trajectory were women (63\%). All carers fitting this trajectory type had one very long care episode spanning more than 25 years on average; in their mid-fifties 44 per cent of these carers had a second care episode and 15 per cent had a third. These later episodes were 
much shorter on average and overlapped for a relatively brief time near the end of the first care episode. Care to high-obligation, close kin dominated the first lengthy care episode. It is the only trajectory in which care to children with long-term health conditions/disability was evident (17.6\%). The defining feature of the career care trajectory is a very long first episode of care to a high-obligation, close family member starting at a relatively early age and spanning more than two decades.

\section{Serial care trajectory}

The serial care trajectory was the least common trajectory type $(\mathrm{N}=144 ; 4 \%)$. It had a relatively early average age of onset (36.2 years), the most episodes (average 3.2 ), long duration (average 31.1 years) and the greatest amount of overlap among care episodes (13.8 years on average). It had the largest proportion of women carers (71.1\%) of all trajectory types. All carers in this trajectory reported two care episodes, two-thirds reported a third episode (66\%), with smaller percentages having a fourth, fifth and sixth episode (data are suppressed for some later episodes because of small cell sizes). The first two care episodes spanned more than 15 years each on average. Although most cared for parents in the first episode, care to siblings, more distant kin and non-kin became more prevalent in subsequent episodes. The defining feature of the serial care trajectory is a lifelong pattern of caring for others (close kin, distant kin and non-kin), often at the same time, that begins in the mid-thirties and spans more than three decades.

\section{Summary}

Findings show that care for family members and friends is not a one-off experience. Most of the care trajectories involved transitions into and out of multiple care episodes spanning broad sweeps of the lifecourse. Findings also indicate that carers can be grouped in meaningful ways and confirm the utility of the four components of care trajectories comprising the independent variables used in the LPA. They also illustrate variability in the ways in which care plays out across the lifecourse. The implications of these findings are explored in the next section of the paper.

\section{Discussion and implications}

Our findings create increased understanding of both patterns of care across the broad sweep of a lifecourse and of diversity in these patterns. The five care trajectories bear similarities to those hypothesised by Keating et al. (2019) but also illustrate some of the complexities of lifecourses of family care not previously theorised. Fundamentally, they illustrate how much more we learn about care by considering lifecourses, not snapshots, of family care.

Three of five trajectories identified in this study resemble generational care trajectories (GCT) as hypothesised by Keating et al. (2019: 152) as 'episodes of care within high obligation close-kin relationships with generational sequencing to cared-for persons'.

Care to parents was first identified as a normative pattern more than 30 years ago (Brody, 1985). The identification of an intensive parent care trajectory both reflects and extends our understanding of this normative pattern. It reflects the 
hypothesised GCT in its finding of episodes of care within older-generation closekin relationships. There is little generational sequencing, although sequencing is evident across multiple, overlapping episodes of care to parents. Knowledge of the existence of such an intensive pattern may be useful as we think about pressures on older workers who are managing employment and parent care or those trying to re-enter employment after withdrawing to provide parent care.

The large volume of research on spouse care suggests that it is the most likely same-generation care experience, especially for women. We did not find a distinct trajectory reflecting spousal care. However, we see two patterns illustrating different configurations of older and same-generation care. The compressed generational pattern reflects expected older or same-generation care relationships. Rather than provided in sequence, the compressed generational pattern comprises predominantly single care episodes to either a parent or spouse. However, given that the sample for this study includes carers as young as 65, it seems likely that some will have subsequent care episodes that may approximate the expected generational sequencing.

The broad generational pattern includes more than one episode of care, also to older or same-generation recipients. However, this generational pattern diverges from the hypothesised GCT by virtue of having a wider set of care relationships to same-generation kin and non-kin, especially in second and third care episodes.

The hypothesised career trajectory was defined as 'a single episode of care of long duration within a high-obligation close-kin relationship' (Keating et al., 2019: 153). Rather than based in normative expectations about care to close kin, it was drawn from evidence of one of the successful drivers of population ageing, that more people both survive and live longer with disabilities. Thus, this trajectory was hypothesised to comprise a continuous and lengthy episode of care, likely to a child needing lifelong support. Our findings did indeed include a career trajectory distinguished by carers starting at an early age and caring for more than three decades. Care to children was reflected among these lengthy care relationships, but so too was parent and spouse care, a reminder that chronic conditions, mental health challenges and traumatic injuries also may require long periods of care.

Career carers are distinguished by starting young and caring long. In contrast, generational patterns span much shorter periods of time at an entirely different stage of the lifecourse. Importantly, career trajectories do not end with this first long episode. At about the same age that generational carers are transitioning into their first episode of care, nearly half of career carers are beginning a second care episode as they enter their third decade of providing care.

Finally, the serial care trajectory was defined as 'multiple episodes of care to diverse care receivers with no normative or predictable sequencing' (Keating et al., 2019: 154). Our findings also show a serial pattern distinguished by numerous care episodes, extensive overlap and long duration. Yet early episodes are predominantly normative parent care. It is only in the third care episode that we see increased evidence of care for those with whom they have loose ties. There are indications that this pattern continues into fourth and subsequent episodes. However, these data cannot be reported because of small cell size. 


\section{Data limitations and opportunities}

Secondary analyses inevitably come with limitations. Trajectories were created based on data on episodes of care across the lifecourse collected retrospectively. The limits of recall data are well documented (Kjellsson et al., 2014). So, for example, memory of early care provision may be incomplete while more onerous or longer-term episodes may be recalled more readily.

In addition, respondents were able to report a maximum of six episodes of care, an operational decision intended to minimise respondent burden and maximise survey response rates. Most (84\%) of our sample reported fewer than six episodes, suggesting that truncation may be a minor problem. However, those who did report six episodes may actually have experienced even more than they could report; others may have additional contributions as they move further along their lifecourse.

We also cannot tell when a lifecourse of care is complete. This is less an issue of data adequacy than of lifecourses continuing to unfold. It does mean, however, that we must be vigilant against inadvertently rendering invisible late-life contributions to care by virtue of constraining the number of care episodes and failing to track care provision in very late life and thereby contributing to the discourse of older people being primarily receivers rather than providers of care.

\section{Advancing theory}

The framing of family care as a lifecourse domain has been useful in several ways. Perhaps most importantly, it incorporates the assumption that time matters. The five trajectories that emerged from our analyses provide the basis for further understanding how time and events unfold in a variety of ways across lifecourses of care. We sense an intensity in parent care due to the multiple and overlapping care responsibilities across a single decade of life. Career care feels quite different, intense because of the relentlessness of a single long episode of care, sometimes to children with long-term disabilities, with additional short periods of care taken on in mid-life, but collectively spanning more than three decades. These findings beg such questions as, does care to fewer recipients that takes up most of the adult lifecourse result in more or less cumulative disadvantage than more episodes packed into a much shorter time?

The place in the lifecourse where trajectories are focused also may make a difference. Compressed, broad and parent care trajectories all occur at a lifecourse stage when we might reasonably expect to take on care responsibilities, primarily when carers are in their fifties and sixties. Might it be that a decade of parent care is experienced differently and perhaps is more readily integrated because it is expected, than career care which begins at a time when we expect to be focused on raising children and building careers and which has the potential to interfere with carers' other lifecourse transitions. In turn, how can the normative timing of parent care be reconciled with the employment lifecourse phase when full engagement in paid work is the norm? It is time to pay attention to how care plays out over the lifecourse, its intersections with employment and family lifecourse domains (Fast et al., 2013), and what diverse care pathways may mean for carers' quality-of-life relationships. 
Time matters in terms of the evolution of relationships as well. In this study we were unable to provide evidence of the unfolding of what Dannefer et al. (2008: 105) have called the 'complex relational nature of care'. How do carers in an intensive parent care trajectory navigate relationships with their siblings while caring in turn for more than one parent? Do children of career carers spend their childhood in the shadow of a demanding care relationship? Over time, might serial carers actually gain social network members as they develop social connections to the networks of the different people they care for? Do broad generational carers become isolated, especially if the persons they care for have dementia? These questions remain unexamined and yet are vitally important to our understanding of whether carers are embedded in convoys of care or are navigating the care lifecourse alone. The challenge is to set aside notions of families as always available (or unavailable) to support one another and to create evidence of the ways in which family relationships are solidified or torn apart by cumulative care experiences.

\section{Moving forward}

\section{Research}

A strong case has been made for attending to full lifecourses rather than snapshots of short segments of them, as is typically the case. We have been able to demonstrate that the structure of care does evolve across the lifecourse and that it evolves in different ways for different individuals. This highlights the limitations of a knowledge base founded on single care episodes. While this study is a good start, it signals rich research opportunities going forward.

We have contributed new knowledge about patterns of care across lifecourses, but care trajectories need further explication. We have captured some of the characteristics of care episodes and their sequencing, specifically periods of concurrent care provision to more than one recipient at the same time. But sequencing also implies patterns in the gaps between care episodes, which we did not examine in this study. In what ways do the gaps between episodes (e.g. their length and timing) further illuminate how patterns of care play out over time? Do carers with long gaps between care episodes revert to their previous lifestyles or are their lifecourses permanently set on a new path?

Our finding that care trajectories also are gendered extends evidence about gender diversity in the provision of family care, challenging beliefs that family care is inevitably the purview of women. Substantial differences in proportions of men carers across profiles suggest the need to understand better what might be gendered expectations about involvement over long periods of time, or to particular relatives or at some stages of the lifecycle. Given that these patterns reflect people who are now aged 65 and older, it will be useful to track differences for future cohorts of carers.

\section{Policy discourses and directions}

Evidence of diverse lifecourse pathways of family care provides a basis for addressing the discourses of 'families by stealth' and 'stealthily disappearing 
families'. For more than a decade academics and policy think tanks have been advocating a lifecourse approach to policy making (Policy Research Initiative, 2004; Bovenberg, 2008). However, if families by stealth is in fact a policy goal to bolster beleaguered health and social care systems, the lack of uptake of such approaches is not surprising. As McDaniel and Bernard (2011: S2) point out, a lifecourse approach to policy making 'can make visible policy options and interventions previously hidden'. Yet, a lifecourse approach to policy development is hardly radical. Social policy is often made to mitigate the impact of risks arising from lifecourse transitions and events on subsequent life chances. For example, policy levers across the employment lifecourse are well developed. There are strategies to enhance labour force engagement of young people, parental leaves to assist new parents and increases in age of pension eligibility to retain older workers.

A policy lens on lifecourses of family care could similarly mitigate risks to carers. The term prudent health and social care (Welsh Government, 2017) is one reflection of a policy aspiration to contain costs while delivering good care. It seems timely then to develop a family care strategy that would support those very people meant to bolster the formal care system. Evidence presented here of variations in lifecourse patterns of care can provide a policy road map to shape these interventions. For example, existing employment policy might well be used as a basis to assist career carers to enter or remain in the labour force early in their care journeys, and equally to protect intensive parent carers from labour force exit with few opportunities to return.

In conclusion, we believe that the evidence presented here of lifecourse trajectories of family care provides a foundation for understanding better patterns of care work across the lifecourse and the gendered nature of care provision. We have much to learn about how these patterns might be associated with risks of poor outcomes for carers, an important next step in determining the sustainability of the family care sector. Further exploration of how care relationships evolve in the context of this care work is essential to deconstructing notions of family care as available but underexploited versus those of families disappearing in the demographic transitions that are the hallmarks of population ageing.

Acknowledgements. Our thanks to Dr Adam Galovan for his assistance with Latent Profile Analysis.

Author contributions. All authors have contributed substantially to the creation of this paper.

Financial support. This work was supported by the Kule Institute of Advanced Study (UOFAB KIASRCG Keating, Health, Wealth and Happiness: Dynamics of Families and a Good Old Age?, 2016-2019); AGE-WELL NCE, Canada's Technology and Aging Network (NCEAGEWELL AW CRP2015WP2.4, Assistive Technology that Cares for the Caregiver, 2015-2020); the Economic and Social Research Council (award number ES/P009255/1, Sustainable Care: Connecting People and Systems, 2017-2021, Principle Investigator Sue Yeandle, University of Sheffield). Financial sponsors played no role in the design, execution, analysis and interpretation of data, or writing of this study.

Conflict of interest. The authors declare no conflicts of interest.

\section{Note}

1 Statistics Canada capped number of care episodes at 6. 


\section{References}

Alwin DF (2012) Integrating varieties of life course concepts. Journals of Gerontology: Psychological Sciences and Social Sciences 67B, 206-220.

Ankuda CK and Levine DA (2016) Trends in caregiving assistance for home-dwelling, functionally impaired older adults in the United States, 1998-2012. Journal of the American Medical Association 316, 218-220.

Bauer J and Sousa-Poza A (2016) Impacts of informal caregiving on caregiver employment, health and family. Population Ageing 8, 113-145.

Bovenberg L (2008) The life-course perspective and social policies: an overview of the issues. CESifo Economic Studies 54, 593-641.

Brody E (1985) Parent care as a normative family stress. The Gerontologist 25, 19-29.

Carers UK (2015) Facts About Carers Policy Briefing. London: Carers UK. Available at https://www.carersuk. org/for-professionals/policy/policy-library?task=download\&file=policy_file\&id=5466.

Carmichael F and Ercolani MG (2016) Unpaid caregiving and paid work over life-courses: different pathways, diverging outcomes. Social Science \& Medicine 156, 1-11.

Cès S, De Almeida Mello J, Macq J, Declercq A and Schmitz O (2017) A systematic review of questionnaires used to measure the time spent on family care for frail older people. International Journal of Care and Caring 1, 227-245.

Connidis IA and Barnett AE (2019) Family Ties and Aging, 3rd Edn. Thousand Oaks, CA: Sage.

Crosignani P (2010) Europe the continent with the lowest fertility. Human Reproduction Update 16, 590-602.

Dannefer D, Stein P, Siders R and Patterson RS (2008) Is that all there is? The concept of care and the dialectic of critique. Journal of Aging Studies 22, 101-108.

Deusdad B, Pace C and Anttonen A (2016) Facing the challenges in the development of long-term care for older people in Europe in the context of an economic crisis. Journal of Social Service Research 42, 144-150.

Dyer WJ and Day RD (2015) Investigating family shared realities with factor mixture modeling. Journal of Marriage and Family 77, 191-208.

Elder GH and George LK (2016) Age, cohorts, and the life course. In Shanahan MJ, Mortimer JT and Kirkpatrick Johnson M (eds), Handbook of the Life Course, Vol. II (Handbooks of Sociology and Social Research). Cham, Switzerland: Springer, pp. 59-85.

Employment and Social Development Canada (2016) Caregiver Readiness. Available at https://www.canada. ca/en/employment-social-development/corporate/seniors/forum/caregiver-readiness-video.html.

Fast JE, Dosman D, Lero D and Lucas S (2013) The Intersection of Caregiving and Employment Across the Life Course, Final Report to Human Resources and Skills Development Canada. Available at https://www. worklifecanada.ca/cms/resources/files/679/Caregiving_and_employment.pdf.

Fingerman KL, Pillemer KA, Silverstein M and Suitor JJ (2012) The baby boomers' intergenerational relationships. The Gerontologist 52, 199-209.

Galovan A and Schramm D (2017) Initial coparenting patterns and postdivorce parent education programming: a latent class analysis. Journal of Divorce \& Remarriage 58, 212-226.

Galovan A, Drouin M and McDaniel BT (2018) Sexting profiles in the United States and Canada: implications for individual and relationship well-being. Computers in Human Behavior 79, 19-29.

Grech AG (2018) What makes pension reforms sustainable? Sustainability 10, 2891.

Grossman B and Webb C (2016) Family support in late life: a review of the literature on aging, disability, and family caregiving. Journal of Family Social Work 19, 348-395.

Hoff A (2015) Current and Future Challenges of Family Care in the UK. London: Foresight, Government Office for Science. Available at https://assets.publishing.service.gov.uk/government/uploads/system/ uploads/attachment_data/file/454514/gs-15-18-future-ageing-family-care-er09.pdf.

Humphries R, Thorlby R, Holder H, Hall P and Charles A (2016) Social Care for Older People: Home Truths. London: The King's Fund and Nuffield Trust. Available at https://www.kingsfund.org.uk/sites/ default/files/field/field_publication_file/Social_care_older_people_Kings_Fund_Sep_2016.pdf.

Jagger C (2017) Living Longer, but with More Care Needs: Late-life Dependency and the Social Care Crisis (British Politics and Policy blog). London: London School of Economics and Political Science. Available at https://blogs.lse.ac.uk/politicsandpolicy/the-social-care-crisis-and-dependency/.

Keating N and Eales J (2017) Social consequences of family care: a scoping review. International Journal of Care and Caring 1, 149-152. 
Keating N, Eales J, Funk L, Fast J and Min J (2019) Life course trajectories of family care. International Journal of Care and Caring 3, 147-163.

Kingston A, Comas-Herrera A and Jagger C (2018) Forecasting the care needs of the older population in England over the next 20 years: estimates from the Population Ageing and Care Simulation (PACSim) modelling study. Lancet Public Health 3, e447-e455.

Kjellsson G, Clark P and Gerdtham UG (2014) Forgetting to remember or remembering to forget: a study of the recall period length in health care survey questions. Journal of Health Economics 35, 34-46.

Kodate $\mathbf{N}$ and Timonen V (2017) Bringing the family in through the back door: the stealthy expansion of family care in Asian and European long-term care policy. Journal of Cross-cultural Gerontology 32, 291-301.

Lund B (2017) Understanding Housing Policy, 3rd Edn. Bristol, UK: Policy Press.

Lunsky Y, Robinson S, Blinkhorn A and Ouellette-Kuntz H (2017) Parents of adults with intellectual and developmental disabilities (IDD) and compound caregiving responsibilities. Journal of Child and Family Studies 26, 1374-1379.

McDaniel S and Bernard P (2011) Life course as a policy lens: challenges and opportunities. Canadian Public Policy 37, supplement 1, S1-S13.

Nylund K, Asparouhov T and Muthén B (2007) Deciding on the number of classes in latent class analysis and growth mixture modeling: a Monte Carlo simulation study. Structural Equation Modeling 14, 535-569.

Office of the United Nations High Commissioner for Human Rights (OHCHR) (2011) Human Rights of Older Persons. Geneva: OHCHR. Available at https://www.ohchr.org/en/issues/olderpersons/pages/ olderpersonsindex.aspx.

Policy Research Initiative (2004) A Life-course Approach to Social Policy Analysis: A Proposed Framework. Ottawa: Policy Research Initiative. Available at http://publications.gc.ca/site/eng/268937/publication. html.

Public Health Agency of Canada (2014) The Chief Public Health Officer's Report on the State of Public Health in Canada: Public Health in the Future. Ottawa: Public Health Agency of Canada. Available at https://www.canada.ca/en/public-health/corporate/publications/chief-public-health-officer-reports-statepublic-health-canada/chief-public-health-officer-report-on-state-public-health-canada-2014-public-healthfuture.html.

Redfoot D, Feinberg L and Houser AN (2013) The Aging of the Baby Boom and the Growing Care Gap: A Look at Future Declines in the Availability of Family Caregivers. Washington, DC: AARP Public Policy Institute. Available at https://www.aarp.org/content/dam/aarp/research/public_policy_institute/ltc/2013/ baby-boom-and-the-growing-care-gap-insight-AARP-ppi-ltc.pdf.

Robertson A (1997) Beyond apocalyptic demography: towards a moral economy of interdependence. Ageing \& Society 17, 425-446.

Scharlach AE, Gustavson K and Dal Santo TS (2007) Assistance received by employed caregivers and their care recipients: who helps care recipients when caregivers work full time? The Gerontologist 47, 752-762.

Sinha M (2013) Portrait of Caregivers, 2012 (Publication No. 89-652-X). Ottawa: Statistics Canada. Available at https://www150.statcan.gc.ca/n1/pub/89-652-x/89-652-x2013001-eng.htm.

Smith K and Victor C (2019) Typologies of loneliness, living alone and social isolation and their associations with physical and mental health. Ageing \& Society 39, 1709-1730.

Stanley L, Kellermanns FW and Zellweger TM (2017) Latent profile analysis: understanding family firm profiles. Family Business Review 30, 84-102.

Starr M and Szebehely M (2017) Working longer, caring harder - the impact of 'ageing-in-place' policies on working carers in the UK and Sweden. International Journal of Care and Caring 1, 115-195.

Tronto J (2017) There is an alternative: homines curans and the limits of neoliberalism. International Journal of Care and Caring 1, 27-43.

Welsh Government (2017) Parliamentary Review of Health and Social Care in Wales Interim Report. Available at https://gov.wales/sites/default/files/publications/2017-07/170714-review-interim-report-en.pdf.

Young H and Grundy E (2008) Longitudinal perspectives on caregiving, employment history and marital status in midlife in England and Wales. Health and Social Care in the Community 16, 388-399.

Cite this article: Fast J, Keating N, Eales J, Kim C, Lee Y (2021). Trajectories of family care over the lifecourse: evidence from Canada. Ageing \& Society 41, 1145-1162. https://doi.org/10.1017/ S0144686X19001806 